\title{
Anticushing Drug Metyrapone Exhibits Specific Interactions with Serine Containing Systems. A Possible Molecular Target?
}

\author{
David Crouzier ${ }^{1}$, Jean-Claude Debouzy ${ }^{1}$, Florian Nachon ${ }^{2}$, Dominique Debouzy ${ }^{3}$, Guy Lallement ${ }^{4}$, \\ Frédéric Canini ${ }^{5}$
}

${ }^{1}$ Effets Biologiques des Rayonnements, IRBA/CRSSA, La Tronche, France; ${ }^{2}$ Unité d'Enzymologie IRBA/CRSSA, La Tronche, France; ${ }^{3}$ Université Pierre Mendes France, St. Martin d’Hères, France; ${ }^{4}$ Département de Toxicologie, IRBA/CRSSA, La Tronche, France; ${ }^{5}$ Unité de Neurophysiologie du Stress, IRBA/CRSSA, La Tronche, France.

Email: david.crouzier@wanadoo.fr

Received August $17^{\text {th }}, 2011$; revised September 13 ${ }^{\text {th }}, 2011$; accepted September $28^{\text {th }}, 2011$.

\begin{abstract}
Metyrapone (2-methyl-1,2-di-3-pyridyl-1-propanone) is a drug largely used as inhibitor of glucocorticoid synthesis. Although its binding to various proteins has been well indentified, its accurate molecular mechanism of action remains unknown. Therefore, the interactions of metyrapone (MET) with various membrane components such as phospholipids, cholesterol, their corresponding polar heads and a model serine containing peptide have been investigated by NMR and ESR methods. It was found that neither cholesterol nor most of the phospholipids tested, nor dimyristin exhibit any interaction with MET, except phosphatidylserine (DMPS). Furthermore, only serine bearing polar head (O-phosphoserine) showed an association with MET (stoechiometry 1:1, Kd =3200M-1). As similar observations were also performed on serine alone and in the presence of the serine containing model peptide, (NASDSDGQDL), a possible implication of these interactions in the binding recognition of MET on serine-containing active site was finally tested and discussed.
\end{abstract}

Keywords: Metyrapone, Membranes, Serine, NMR, ESR, Interactions

\section{Introduction}

In the clinical field, metyrapone (2-methyl-1,2-di-3-pyridyl-1-propanone MET), an inhibitor of glucocorticoid synthesis [1], is widely used to treat the Cushing disease $[2,3]$. Since high blood corticosterone levels have been linked to a depressive mood [4], metyrapone is also used to treat Cushing related mental disturbances [5] and major depression [6-9]. However, metyrapone exhibits other properties highlighted by preclinical studies that can not be explained by its action on the corticotrope axis. At the physiological level, metyrapone injection is followed by a slight hypothermia [10] not reversed by glucocorticoid supplementation [11], a decreased locomotion [12], an enhanced arousal [13] together with biological signs of stress [14]. The latter does not mask the protective effect of metyrapone against psychological stressors $[15,16]$ and physiological stressors such as brain ischemia $[17,18]$ and excitotoxicity [19]. At the cell level, metyrapone modify the energy metabolism [10] with a decreased use of glucose [20-21] and alters the mitochondrial function- ing [22]. Lastly, metyrapone also modify the detoxification as it modifies the expression of numerous cytochrome P450 such as CYP1A1 and CYP 3A [23].

Besides these integrated levels, the molecular support, i.e. the identification or the molecular target, still failed. Metyrapone profoundly modify the steroid metabolism through its inhibitory activity on the $11 \beta$ hydroxylase (CYP11B1), [1], 17 $\beta$ hydroxysteroid deshydrogenase (17 $\beta$-HSD) [24] and the $11 \beta$-HSD [25]. Metyrapone also inhibits P450 [26] in numerous species [27]. Its inhibitory effect is not specific as it targets the CYP11B1 [28] and the CYP3A [29], but also other enzymes such as lipooxygenase [30], guanylate cyclase [31] or nitric oxide synthetase as a member of cytochrome P450-like hemoprotein [32]. Some works have focused on the mechanisms by which metyrapone interacts with P450. Its fixation on P450 is independent from the redox state of the enzyme and the availability of oxygen [33,34] and does not modify the conformation of the protein P450A3 $[35,36]$. Another mechanisms suggested was the possible 
implication of membrane components, phospholipids or cholesterol $[37,38]$. The investigation of this hypothesis was the starting point of the present study. NMR and ESR experiments were recorded on synthetic multilayers of phospholipids and sphingolipids, their building blocks (polar head groups and acyl chain backbone) and cholesterol. This selection led to identify a potential target and to finally observe the interactions of MET with a model peptide containing this molecular target, serine.

\section{Materials and Methods}

\subsection{Chemicals}

Dymiristoyl phosphatitdylcholine (DMPC), dymiristoyl phosphatidylethanolamine (DMPE), dymiristoyl phosphatidylserine (DMPS), dimyristin, bovine brain sphingomyelin, ceramids, galactocérébrosides, dipalmitoylphosphatidylglycerol DPPG, phosphorylcholin O-phosphoserine, serine, O-phosphocolamine, ethanolamine were purchased from Sigma-Aldrich (La Verpillère, France) and used without purification.

The model peptide N10L: Asn-Ala-Ser-Asp-Ser-AspSer-Gly-Gln-Asp-Leu (NASDSDGQDL) was purchased from NeoMPS, Stasbourg, France. Proton attribution, and purity control were performed in D2O by using classical NMR technics (TOCSY, HMBC, HMQC, nOesy [39]) at 298 K. No stable conformation of the peptide could be identified at this step.

MET was from Sigma. Purity control and proton assignment were obtained by classical NMR methods $(1 \mathrm{H}$, COSY, HMBC, HMQC [39]), as indicated on the Figure 2(c).

\subsection{Vesicles Preparation}

\subsubsection{Multilayer Vesicles (MLV)}

The phospholipids or sphingolipids in their chloroformic solution were evaporated to a film and resuspended in pure $\mathrm{D}_{2} \mathrm{O}$. The liposomes were formed by fast freezing and thawing cycles. The final lipid concentration was 50 $\mathrm{mM}$ and MET/lipid molar ratio were fixed to 1:12, 1:10, 1:7, 1:4 M/M.

\subsubsection{Small Unilamelar Vesicle (SUV)}

Phospholopids in theirs chloroformic solution $(10 \mathrm{mg} / \mathrm{ml})$ were lyophylized and resuspended in pure $\mathrm{D}_{2} \mathrm{O}$ for a final lipid concentration of $10 \mathrm{mM}$. SUV were formed by 1 Hour bath sonication. For MET containing SUV, the respective chloroformic solutions were mixed before lyophylization.

\subsection{NMR Experiments}

High resolution NMR experiments. Standard 1H-NMR experiments were recorded at $298 \mathrm{~K}$ on a Bruker AM-
400 spectrometer using a $4000 \mathrm{~Hz}$ spectral width, $32 \mathrm{~K}$ digitization points, a recycling delay of 2 sec. A presaturation of water resonance was used for all the experiments. Phase sensitive NOESY NMR experiments were recorded at $298 \mathrm{~K}$ to detect MET-serine and MET-peptide vicinities (dipolar correlations) with a presaturation of the solvent resonance and mixing times of $250 \mathrm{~ms}$.

Solid-state ${ }^{31} \mathrm{P}-\mathrm{NMR}$ experiments in multilayers (MLV) were performed at $162 \mathrm{MHz}$. Phosphorus spectra were recorded using a dipolar echo sequence $(\pi / 2-\mathrm{t}-\pi-\mathrm{t})$ [40] with a $\mathrm{t}$ value of $12 \mu \mathrm{sec}$, a $\pi / 2$ pulse of $3.8 \mu \mathrm{s}$ and a broadband two level proton decoupling. Phosphoric acid (85\%) was used as external reference. The sample temperature was regulated within $1^{\circ} \mathrm{C}$ by a BVT-1000 unit.

Job plots. For all interaction experiments, in a first step, a coarse screening was used by preparing equimolar (5 $\mathrm{mM}$ ) host/MET mixtures and sample containing excess of MET (9/1, M/M). In the absence of any spectral modification (mainly chemical shift, peak intensity and linewidth), the affinity was considered as negligible and the study was not followed further. Fast exchange kinetics were identified on the spectra by both MET and host chemical shift variations upon MET addition, and the classical method described by Job [41,42] was used to draw the stoechiometry of the complex. Besides, mathematic determination method SIMPLEX (EXPREX, or MURIEL-X) algorithms generously given by Bruno Perly, CEA Saclay, France, for strong complex and in order to draw estimations of the apparent association constant [43].

\subsection{ESR Experiments: Spin Label Study}

Effect of MET on DMPS SUV fluidity was assessed by ESR spin label experiments. Two spin labels (Sigma France) were used: 5-nitroxide stearate (5 NS) and 16nitroxide stearate (16 NS). This fatty acids self incorporate the SUV and the nitroxide groups provide information of motional freedom of the label in the system. So the former probes the superficial part of the membrane layer, the latter in its hydrophobic core.

The experiments were performed on SUV made with DMPS $10 \mathrm{mg} / \mathrm{mL} .1 \mathrm{mg}$ of MET was added in $500 \mu \mathrm{L}$ SUV solution. $200 \mu \mathrm{l}$ of the SUV control solution and SUV MET solution were then labelled with $10 \mu \mathrm{L}$ of spin label solution (5 NS $5 \times 10^{-3} \mathrm{M}$ or $16 \mathrm{NS} 5 \times 10^{-3} \mathrm{M}$ ). After 30 min incubation at room temperature, sample was transferred by capillarity in $20 \mu \mathrm{L}$ Pyrex capillary tube. This tube was placed in a $3 \mathrm{~mm}$ diameter quartz holder, and insert into the cavity of the ESR spectrometer.

The ESR spectra were recorded at different controlled temperature (303, 308, 310, 313, 315, 318 and $323 \mathrm{~K}$ ) with the following conditions: microwave power 20.00 
$\mathrm{mW}$, modulation frequency $100 \mathrm{kHz}$, modulation amplitude $2.05 \mathrm{G}$, receiver gain $6.3 \times 10^{5}$ conversion time $81.92 \mathrm{~ms}$, time constant $81.92 \mathrm{~ms}$. Sweep range was 100 $\mathrm{G}$ with a central field value of $3435 \mathrm{G}$ for 5 NS probe, and in the same condition except, modulation amplitude $1.03 \mathrm{G}$, receiver gain $10^{5}$ conversion time $40.96 \mathrm{~ms}$, time constant $81.92 \mathrm{~ms}$ for 16 NS probe.

The complete membrane incorporation of the spin labels was ascertained by the absence on the spectra of the extremely resolved ESR lines corresponding to free rotating markers.

5 NS experimentations: The values of outer and inner hyperfine splitting were measured $\left(2 \mathrm{~T}_{/ /}\right.$and $2 \mathrm{~T}_{\perp}$ respecttively), on ESR spectra (Figure 3(b)), and order parameter $\mathrm{S}$ was calculated following the equation [44]:

$$
\mathrm{S}=1.723 \times \frac{\mathrm{T}_{/ /}-\left(\mathrm{T}_{\perp}+\mathrm{C}\right)}{\mathrm{T}_{/ /}+2\left(\mathrm{~T}_{\perp}+\mathrm{C}\right)}
$$

with

$$
\mathrm{C}=1.4-0.053 \times\left(\mathrm{T}_{/ /}-\mathrm{T}_{\perp}\right)
$$

The increase in the order parameter value means a decrease of local membrane fluidity.

16 NS experimentations: The changes in freedom motion of 16 NS were analysed with the calculation of $\tau_{c}$, the rotational correlation time. $\tau_{c}$ was calculated following the formula [45]:

$$
\mathrm{Tc}=\mathrm{K} \times \Delta \mathrm{W}_{0}\left(\sqrt{\left(\mathrm{h}_{\mathrm{o}} / \mathrm{h}_{-1}\right)}-1\right)
$$

with

$$
\mathrm{K}=6.5 \times 10^{-10} \mathrm{~s} \cdot \mathrm{G}^{-1}
$$

In this formula, $\Delta \mathrm{W}_{0}$ is the peak-to-peak line width of the central line; $h_{0}$ and $h_{-1}$ are the peak height of the central and high-field lines respectively (Figure 3(d)).

The increase in the rotational correlation time means a decrease of local membrane fluidity.

\section{Results}

\section{1. ${ }^{31} \mathrm{P}$-NMR Experiments in MLV}

A first attempt for MET affinity and interaction screening was performed by using phospholipid dispersions as membrane model. This model allows to observe the structural and dynamics consequences of the presence of MET at the polar head $\left({ }^{31} \mathrm{P}-\mathrm{NMR}\right)$ by recording NMR spectra under different temperature conditions. Thus the dependence of the interactions with MET following the nature of the polar head group was tested by using different phospholipids, i.e. DMPC, sphingomyeline, DMPE, DMPS, DPPG, and also galactocerebrosides and ceramides. At this point, it is noteworthy to recall several basic principles about ${ }^{31} \mathrm{P}$-NMR in membranes.

${ }^{31} \mathrm{P}$-NMR chemical shift (the resonance frequency) depends on the orientation of phosphorus nuclei in the field (shielding). The chemical shift difference between the low field and the highfield edges of a ${ }^{31} \mathrm{P}-\mathrm{NMR}$ spectrum is called Chemical Shift Anisotropy (CSA, ppm) and is directly related to the fluidity-reorientation-at the polar head level where the phosphorus nuclei are located. On such spectra a mobile phosphorus group gives a single narrow resonance (several $\mathrm{Hz}$ ) as detected in true solutions or for small structures (micelles), while phosphorus groups in solid state gives extremely broad contributions (CSA values exceeding $100 \mathrm{ppm}$ ). Note that membrane fluidity increases (and CSA decreases) with temperature, with a special jump at the transition temperature between gel phase and liquid crystal structure (e.g. around $297 \mathrm{~K}$ for DMPC [46]). Thus the plot of CSA as a function of temperature provides a good overview of membrane dynamics at the polar head level where phosphorus nuclei are located, while the lineshape allows identifying the overall membrane organization (bilayer, hexagonal, isotropic phases). Such plots are presented on the traces of the Figure 1 (top traces).

The bottom spectrum (Figure 1, column A) shows the spectrum of pure DMPC dispersion (MLV), typical of an axia11y symmetric powder pattern, with a chemical shift anisotropy of $65 \mathrm{ppm}$, classical of a phospholipid (here DMPC) bilayers in their liquid crystalline phase around phase transition (297 K) [47].

As expected for pure DMPC dispersions a CSA decrease (around 18 - 20 ppm) was measured on pure DMPC systems by increasing the temperature (and the membrane fluidity) with the transition-related jump around $297 \mathrm{~K}$ [48]. This was also the case for MET containing MLV (MET/DMPC ratios of $1 / 10$ and up to $1 / 4 \mathrm{M} / \mathrm{M}$, middle and top traces, column A). Also temperature dependence of CSA values was found almost surperimposed on the entire temperature range Figure 1(c)). Besides, no significant isotropic contribution typical of detergent effect was observed, thus finally indicating the absence of any interaction with the membrane. Similarly, no interaction with MET was found for cholesterol (up to $20 \%$ ) containing DMPC dispersions and also for galactocerebrosides, ceramides, and DPPG MLV (not shown). Besides, when DMPE systems were used, only a limited increase in the fluidity (i.e. a limited CSA reduction) was observed all over the temperature range, never exceeding 2ppm, even for high MET/DMPE ratios of $1 / 4$.

Such was not the case for the spectra recorded under the same conditions on DMPS (Figures 1(b)-(d)) dispersions in the presence of MET. As expected, pure DMPS dispersions gave typical spectra of bilayer structures (see 
Figure 1(b) bottom), with a decrease of the CSA with temperature. The same spectra recorded on MET containing DMPS systems resulted in a reduction of the CSA for MET/DMPS molar ratios exceeding $\mathrm{R}=1 / 10 \mathrm{M} / \mathrm{M}$ (trace of the Figure 1(d)), while an isotropic contribution appeared for higher $\mathrm{R}$ values, with a relative contribution

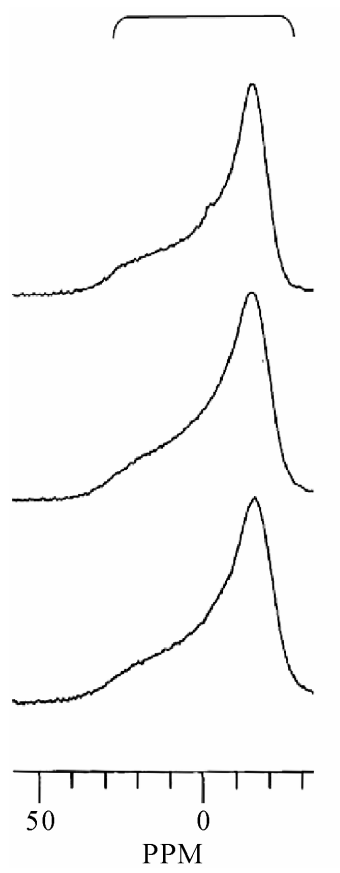

(a)

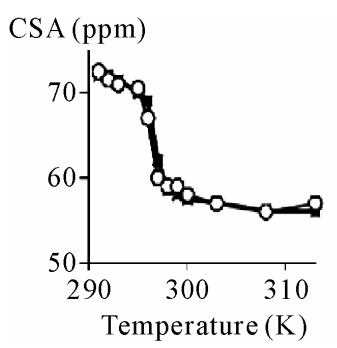

(c) (b)

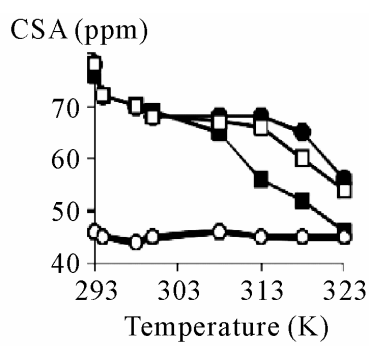

(d)

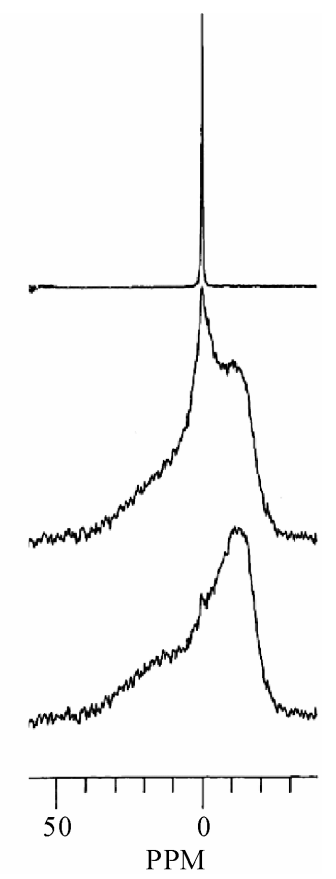

Figure 1. ${ }^{31} \mathrm{P}-\mathrm{NMR}$ (a) spectra of DMPC dispersion (50 mM, $D_{2} \mathrm{O}$ ) at $297 \mathrm{~K}$, pure (bottom trace) and in the presence of MET, molar ratios of $R=1 / 10$ and $1 / 4, M / M$, (middle and top traces, respectively); horizontal bracket represent the CSA; (b) spectra of DMPS dispersion $\left(50 \mathrm{mM}, \mathrm{D}_{2} \mathrm{O}\right)$ at 313 $\mathrm{K}$, pure (bottom trace) and in the presence of MET, molar ratios of 1/10 and 1/4, M/M, (middle and top traces, respecttively; (c) plot of temperature dependence CSA measured on DMPC dispersion spectra of DMPC (O), and in the presence of MET, $R=1 / 4 \mathrm{M} / \mathrm{M}$ (घ); (d) plot of temperature dependence CSA measured on DMPS dispersion spectra of

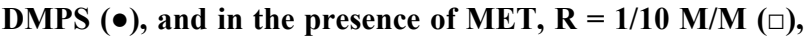
and $R=1 / 7 \mathrm{M} / \mathrm{M}(\square)$; bottom trace $(\bullet)$ represents the line width of the isotropic contribution observed at $R=1 / 4$ M/M. being developed at the expense of the main structure (Figure 1(b) middle and top traces). Finally, a single line of less than $50 \mathrm{~Hz}$ with was exclusively detected for $\mathrm{R}=$ $1 / 4$, indicating that the native structure had been completely replaced by very mobile systems of high fluidity, consistent with a detergent effect or micelle formation.

At this step, the existence of MET/DMPS bilayers appears as highly probable. In order to obtain more precisions, the different building blocks of the phospho- or sphingolipids were considered separately, i.e. the polar headgroups and the diacylglycerol backbone. These experiments are the topic of the next section.

\section{2. ${ }^{1}$ H-NMR and ESR of Polar Headgroups and Chains}

Headgroups. As both polar groups and MET are soluble in $\mathrm{D}_{2} \mathrm{O}$, the first step was achieved by recording spectra on equimolar mixtures and compared to those of pure species of O-phosphocholine (OPC), O-phosphoserin (OPS), O-phosphocolamine(OPCO), and sphingosine. A special care was paid to the aromatic resonances of MET, clearly isolated in the 7 - 9 ppm region (see Figure 2(a) for MET structure and nomenclature, bottom trace for the corresponding spectrum of MET).

In the case of OPC, and sphingosine, as no detectable spectrum variation was observed both in chemical shift and linewidth even MET was present in excess (9/1 M/M ratios MET/headgroup) it was assumed that no interacttion occurred and the investigation was not studied further.

OPCO-MET systems only provided minor chemical shift variations that did not allow to propose a precise mode of interaction, stoechiometry or affinity constant (attempts made using Benesi-Hidebrandt method only showed it should not excess $30 \mathrm{M}^{-1}$ ). The affinity of MET for OPCO was thus considered as very weak.

As significant chemical shift variations were observed on both OPS and MET resonances upon addition of OPS, the continuous variations method was used by recording spectra of different molar ratios MET/OPS, keeping total concentration constant ( $5 \mathrm{mM}$, see examples of such spectra on Figure 2). This allowed us to use the method to characterize these interactions, as classically described by Job [41].

In such plots, the curves built using concentration weighted chemical shift variations as a function of the molar fraction show a maximum for the molar fraction corresponding to the stoechiometry, here 0.5, which means a $1 / 1$ association (2B). This also allowed the use of numerical simulations (EXPREX2 [43]) that gave an apparent association constant of $3200 \mathrm{M}^{-1}$.

In order to detect spatial vicinities between MET and 


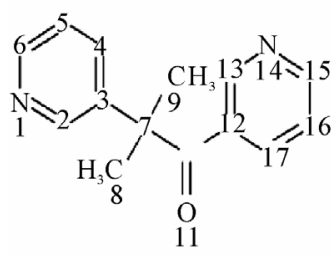

(a)

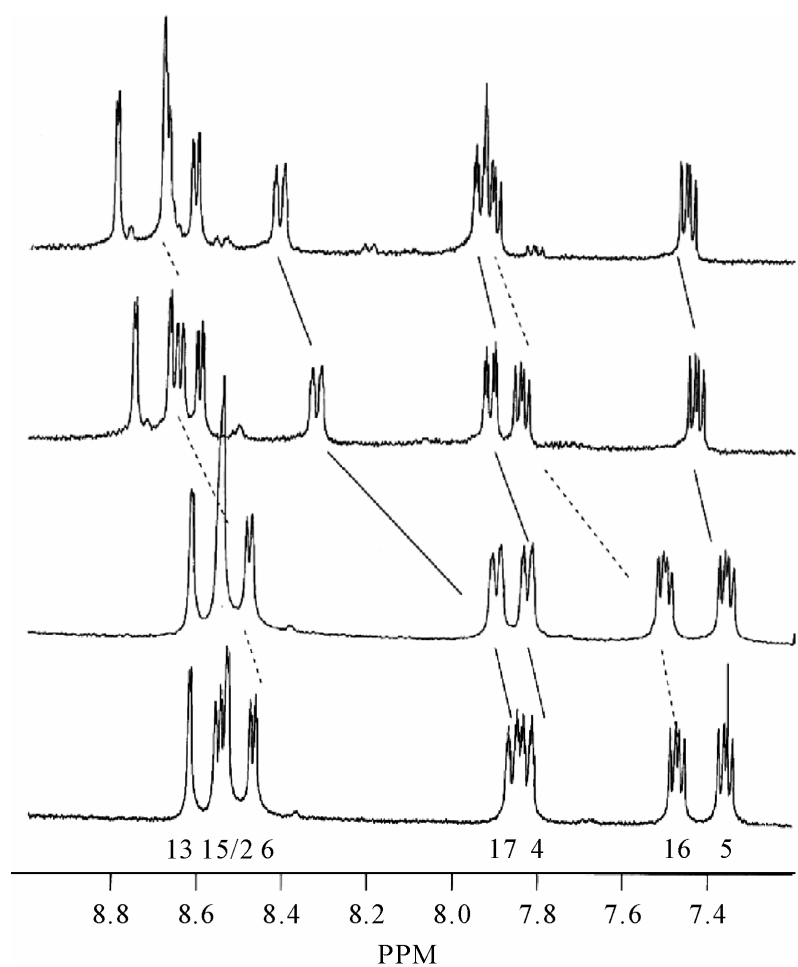

(c)

Figure 2. (a) Metyrapone (MET) formula and proton nomenclature (b) Job-Plots built from concentration-weighted chemical shift variations $(\mathrm{mM} * \mathrm{~Hz})$ as a function of molar fraction (F), for H5 (7.356 ppm, घ), H4 (7.82 ppm, •), H16 (7.47 ppm, $\circ$ ) protons of MET or H2" proton of phosphoserine (4.19 ppm, $\Delta), 298 \mathrm{~K} \mathrm{D}_{2} \mathrm{O}$. The total concentrations were kept at $5 \mathrm{mM}$. Bottom traces with proton numbering below (from bottom to top): aromatic part of the ${ }^{1} \mathrm{H}-\mathrm{NMR}$ spectra of MET (bottom trace), and in the presence of O-phosphoserine (corresponding molar ratios MET/OPS of $1: 0,9 / 1 ; 3 / 2$ and $1 / 1$, respectively.

OPS, nOesy experiments (mixing time of $250 \mathrm{~ms}$ ) were then recorded on the $1 / 1$ mixture. Hence weak dipolar correlations were found between one of methylenic protons (4.22 ppm) of OPS and H16, H15 and H13 protons of MET, and also between $\mathrm{CH} \alpha,(4.15$ ppm) and $\mathrm{H} 15$ not shown). However, molecular dynamics simulations could not lead to propose any stable conformation.

Diacylglycerol backbone. In order to observe chains interaction without any polar head contribution, dispersions of dimyristin and dipalmitin were prepared as for phospholipid MLV. As the ${ }^{1} \mathrm{H}$ spectra recorded on the dispersions containing $\mathrm{MET}(\mathrm{R}=1 / 1 \mathrm{M} / \mathrm{M})$ were the single sum of the spectra of pure dispersions and MET recorded separately under the same conditions, it was concluded that no interaction occurred at the molecular level (not shown).

\subsection{ESR Experiments}

Spin label experiments were then realised to investigate the membrane fluidity in different temperature conditions at the chain level. Two probes were separately used, 5 NS gate information about superficial membrane fluidity, while 16 NS concerned the inner membrane region. The overall result (Figures 3(a) and (c)) shows an increase in the mobility of the two probes contribution in the two groups with the temperature increase. As previously described in SUV DMPS model $[47,49]$, the phase transition in control groups occurs near $313 \mathrm{~K}$.

The ESR results were found in full agreement with the experiments recorded by NMR: hence, no interaction with phospholipids and sphingolipids except DMPS was found. In this latter case, an increase in the mobility of the two probes contribution was found when MET was added to DMPS solution.

5 NS results are drawn Figure 3(a). An overhall increase of the membrane fluidity and a shift of the phase transition, 5 degrees lower, could be observed in the MET group.

In the inner compartment, 16NS results (Figure 3(c)) show a major effect of MET with a total vanishing of phase transition and a strong increase of the membrane between 303 and $313 \mathrm{~K}$. At the highest temperature (above $315 \mathrm{~K}$ ) the rotational correlation time of the control group reached the same value as MET group.

However, a true interaction between free serine and MET was very probable. Under a biological point of view, it was important to know if MET could also have interactions with a serine group engaged in a peptide structure. This was tested by using a reference decapeptide NASDSDGQDL as target.

\subsection{Interactions with the Model Peptide NASDSDGQDL}

After purity control and attribution of peptide protons using classical NMR methods [50], the same method as before was used on equimolar mixtures of MET/peptide. By comparison with the spectrum of pure MET (Figure 4(a)) significant chemical shift variations were observed on the MET/peptide sample, as shown on Figure 4(a), similar as with OPS/MET preparations. Moreover, the 

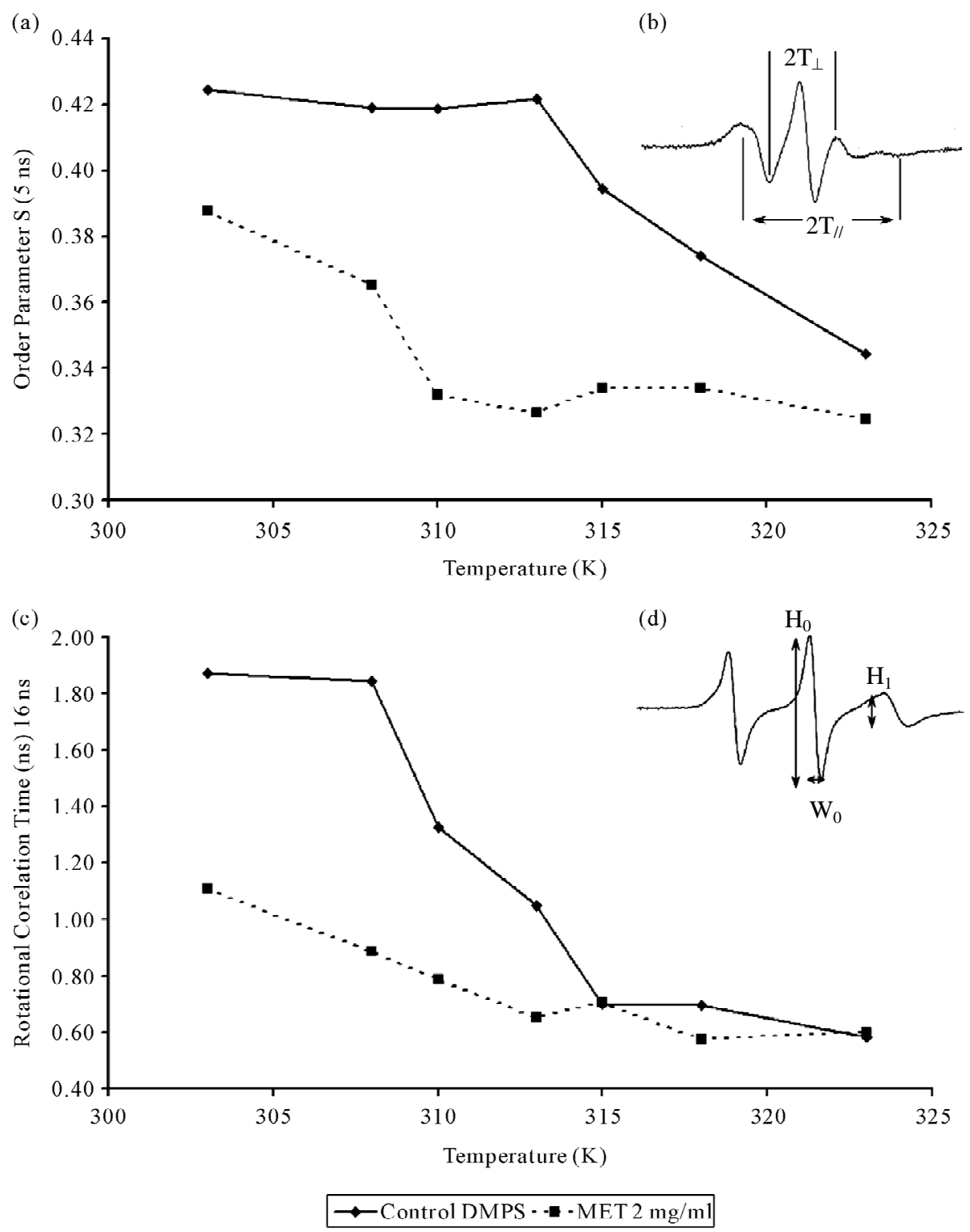

Figure 3. ESR spin labeling experiment: (a) temperature dependence of the order parameter (5 NS) for pure DMPS (black diamond full line) and in the presence of MET $2 \mathrm{mg} / \mathrm{ml}$ (black square, dashed line); (b) typical 5 NS spectrum parameter used for order parameter estimation are inner $\left(2 \mathrm{~T}_{\perp}\right)$ and outer hyperfine $\left(2 \mathrm{~T}_{/ /}\right)$splitting; (c) temperature dependence of the rotational correlation time (16 NS) for pure DMPC and in the presence of MET $2 \mathrm{mg} / \mathrm{ml}$; (d) typical 16 NS spectrum, parameter used for rotational correlation time was central peak intensity $\mathrm{H}_{0}$, High field peak intensity and the width of the mid-field line $\mathbf{W}_{0}$.

nOesy experiment then recorded also showed weak dipolar connectivities, mainly between H15, H6 and several peptide protons, suggesting vicinities in the $4-6 \AA$. However, whereas MET well exhibited some vicinities with serine groups, others of more strong intensity were also present with Gly and Gln aminoacids.

\section{Discussion}

The present work primarily investigated the interactions of MET with membrane components, phospholipids, sphingolipids or cholesterol, as evoqued in the literature [51]. The use of multibilayers (dispersions prepared by the freezing-thawing method [52]) combined with solidstate ${ }^{31} \mathrm{P}$-NMR spectroscopy allows to investigate both dynamics and structural collective properties of the bilayers. Such a method allows to easily obtain a screening the specificity of interactions with a given phospholipid system. In the present case, as preliminary tests performed 


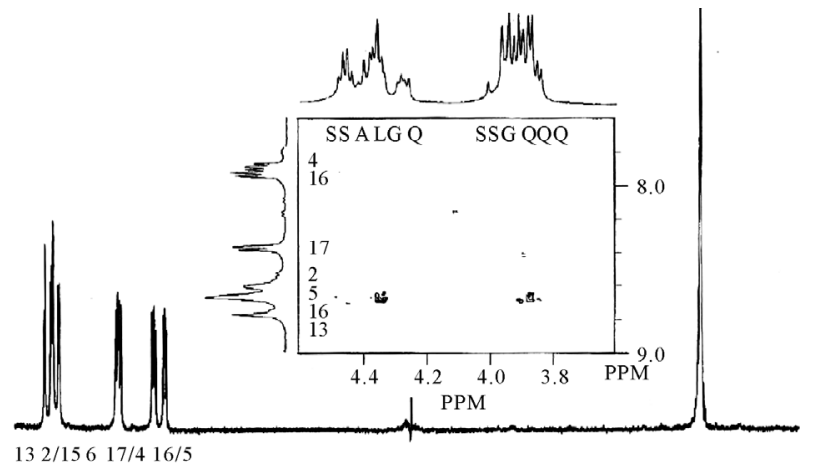

(a)

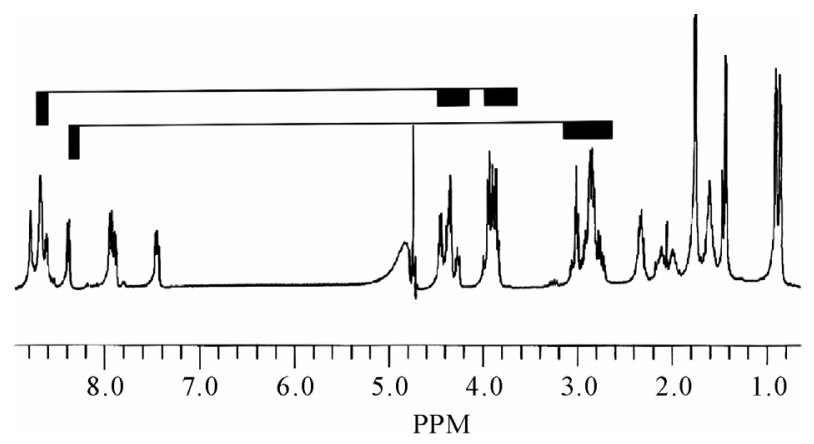

(b)

Figure 4. ${ }^{1} \mathrm{H}-\mathrm{NMR}$ spectrum of pure MET, $5 \mathrm{mM}, 298 \mathrm{~K}$, $\mathrm{D}_{2} \mathrm{O}$; (b) same conditions as (a), on a NASDDGQDL/MET preparation (1/1 M/M); Bars indicate dipolar correlations between labelled groups. Inset shows a partial 2D-nOeSY map recorded on the same sample.

on "standard" lecithin or DMPC small unilamellar vesicles [53], or permeabilization tests on large unilamellar vesicles [54] had given no arguments, an investigation a possible specificity was required. Among the main lipid species tested, MET interactions with DMPS systems were evidenced (from a simple fluidization for low amounts of MET to a drastic detergent effect for molar ratios exceeding $1 / 7 \mathrm{M} / \mathrm{M}$ ), and could be precised by studying separately the interactions of MET with lipid building blocks: while the lipidic part seemed not to play any role in the interaction with MET, dramatic spectral modifications were noted in the presence of phosphoserine; moreover, spatial connectivities were identified between aromatic protons of the second cycle of MET (see nomenclature Figure 2) and serine groups, even if the fast exchange mode of interaction - that allowed job-plot constructions [55] — could not allow to determine a stable conformation via molecular dynamics calculations. By comparing ${ }^{31} \mathrm{P}-\mathrm{NMR}$ and ESR results, one can observe that MET induces dramatic changes at the polar head level $\left({ }^{31} \mathrm{P}\right)$, whereas similar liquefying effects were found part of the chain (5 NS), while the same observation could be done at high temperature-at the deep part level of the layer (16 NS). It can thus been proposed that the target for MET interaction is mainly located at the polar head level, were serine groups are present, and that the overall membrane destructuration would result from dynamics perturbation and sterical hindrance, as observed for cholesterol-phospholipid interactions [56]. Nevertheless this interaction with a given amino acid-serinewould also be consistant with the recognition by MET of a signaling site of the target protein guanylate cyclase-a serine containing protein [31]. Thus an attempt was made to test the interaction of MET with a serine containing peptide, i.e. to test the consequences for interactions with MET to use a serine engaged in a peptide bound. Despite the presence of true interactions with MET (close to those observed with phosphoserine), and the observation of intermolecular nOes, it was not possible to ascertain any specificity in this case. Especially, dipolar connectivities were also noted with Gly and Gln, suggesting that MET interactions with aminoacids would be at least not specific of serine moieties. However, it must be kept in mind that the peptide used is of small size, hydrophilic and structureless, that means not favorable for any stable conformation or molecular associations found in proteins.

Hence, the future experiments now on course will have to deal with a more realistic model, i.e. a "serin-pocket" containing peptide with more stable supramolecular organization.

\section{Acknowledgements}

Thanks to Will Sorin for helpful discussions and Mrs. C. Bigname for fruitful collaboration.

\section{REFERENCES}

[1] J. S. Jenkins, J. W. Meakin, D. H. Nelson and G. W. Thorn, "Inhibition of Adrenal Steroid 11-Oxygenation in the Dog,” Science, Vol. 128, No. 3322, 1958, pp. 478-479. doi:10.1126/science.128.3322.478-a

[2] J. A. Verhelst, P. J. Trainer, T. A. Howlett, L. Perry, L. H. Rees, A. B. Grossman, J. A. H. Wass and G. M. Besser, "Short and Long-Term Responses to Metyrapone in the Medical Management of 91 Patients with Cushing's Syndrome," Clinical Endocrinology, Vol. 35, No. 2, 1991, pp. 169-178.

[3] N. Sonino, M. Boscaro, G. Ambrose, G. Merola and F. Mantero, "Prolonged Treatment of Cushing's Disease with Metyrapone and Aminoglutethimide," IRCS Medical Sciences, Vol. 14, 1986, pp. 485-486.

[4] R. Yehuda, "Post-Traumatic Stress Disorder," The New England Journal of Medicine, Vol. 346, No. 2, 2002, pp. 108-114. doi:10.1056/NEJMra012941

[5] P. C. Myhill, S. Starkstein, T. Annus and B. B. Yeap, 
"Reduction in Salivary Cortisol Concentration Correlates with Resolution of Psychosis in Cushing's Syndrome," Journal of Neuropsychiatry and Clinical Neuroscience, Vol. 20, No. 1, 2008, pp. 113-115. doi:10.1176/appi.neuropsych.20.1.113

[6] B. E. P. Murphy, V. Dhar, A. M. Ghadirian, G. Chouinard and R. Keller, "Response to Steroid Suppression in Major Depression Resistant to Antidepressant Therapy," Journal of Clinical Psychopharmacology, Vol. 11, No. 2, 1991, pp. 121-126.

[7] Z. Rogoz, G. Skuza, J. Wójcikowski, W. A. Daniel, A. Wróbel, D. Dudek and A. Zieba, "Effect of Metyrapone Supplementation on Imipramine Therapy in Patients with Treatment Resistant Unipolar Depression," Polish Journal of Pharmacology, Vol. 56, No. 6, 2004, pp. 849-855.

[8] O. M. Wolkowitz and V. I. Reus, "Treatment of Depression with Antiglucocorticoid Drugs," Psychosomatic Medicine, Vol. 61, No. 5, 1999, pp. 698-711.

[9] B. E. P. Murphy, "Steroid and Depression," Journal of Steroid Biochemistry and Molecular Biology, Vol. 38, No. 5, 1991, pp. 537-559. doi:10.1016/0960-0760(91)90312-S

[10] R. Werner, "Effect of Metopirone-Ditartrate on Thermogenesis in the Guinea-Pig," Comparative Biochemistry and Physiology Part C, Vol. 90, No. 2, 1988, pp. 445-450. doi:10.1016/0742-8413(88)90025-4

[11] J.-B. Drouet, V. Michel, A. Peinnequin, A. Alonso, N. Fidier, R. Maury, A. Buguet, R. Cespuglio and F. Canini, "Metyrapone Blunts Stress-Induced Hyperthermia and Increased Locomotor Activity Independently of Glucocorticoids and Neurosteroids,” Psychoneuroendocrinology, Vol. 35, No. 9, 2010, pp. 1299-1310. doi:10.1016/j.psyneuen.2010.03.001

[12] F. Canini, S. Brahimia, J.-B. Drouet, V. Michel, A. Alonso, A. Buguet and R. Cespuglio, "Metyrapone Decreases Locomotion Acutely," Neuroscience Letters, Vol. 457, No. 1, 2009, pp. 41-44. doi:10.1016/j.neulet.2009.03.103

[13] J.-B. Drouet, C. Rousset, R. Maury, V. Michel, A. Buguet, R. Cespuglio and F. Canini, "Single Administration of Metyrapone Modifies Sleep-Wake Patterns in the Rat," European Journal of Pharmacology, Vol. 652 No. 1-3, 2010, pp. 60-64. doi:10.1016/j.ejphar.2010.10.071

[14] D. Rottlant, S. Ons, J. Carrasco and A. Armario, "Evidence That Metyrapone Can Act as a stressor: Effect on Pituitary-Adrenal Hormones, Plasma Glucose and Brain C-Fos Induction,” European Journal of Neuroscience, Vol. 16, No. 4, 2002, pp. 693-700. doi:10.1046/j.1460-9568.2002.02120.x

[15] M. Baez, I. Siriczman and M. Volosin, "Corticosterone Is Involved in Foot Shock-Induced Inactivity in Rats," Physiology and Behavior, Vol. 60, No. 3, 1996, pp. 795-801. doi:10.1016/0031-9384(96)00025-X

[16] N. Calvo, I. D. Martijena, V. A. Molina and M. Volosin, "Metyrapone Pretreatment Prevents the Behavioral and Neurochemical Sequelae Induced by Stress," Brain Research, Vol. 800, No. 2, 1998, pp. 227-235. doi:10.1016/S0006-8993(98)00515-0
[17] H. J. Krugers, S. Maslam, J. Korf and M. Joëls, “The Corticosterone Synthesis Inhibitor Metyrapone Prevents Hypoxia/Ischemia-Induced Loss of Synaptic Function in the Rat Hippocampus,” Stroke, Vol. 31, No. 5, 2000, pp. 1162-1172. doi:10.1161/01.STR.31.5.1162

[18] V. L. Smith-Swintosky, L. C. Pettigrew, R. M. Sapolsky, C. Phares, S. D. Craddock, S. M. Brooke and M. P. Mattson, "Metyrapone, an Inhibitor of Glucocorticoid Production, Reduces Brain Injury Induced by Focal and Global Ischemia and Seizures," Journal of Cerebral Blood Flow and Metabolism, Vol. 16, No. 4, 1996, pp. 585-598. doi:10.1097/00004647-199607000-00008

[19] B. A. Stein and R. M. Sapolsky, "Chemical Adrenalectomy Reduces Hippocampal Damage Induced by Kainic Acid,” Brain Research, Vol. 473, No. 1, 1988, pp. 175-180. doi:10.1016/0006-8993(88)90332-0

[20] O. D. Bruno, P. Metzger and W. J. Malaisse, "Inhibitory Effect of Metyrapone on Glucose Utilization by Brain and Muscle and on Insulin Release by the Pancreas," Acta Endocrinologica, Vol. 70, No. 4, 1972, pp. 710-718.

[21] G.-F. Kahl and K. J. Netter, "The Effect of Metyrapone on Cellular Respiration and Microsomal Drug Oxidation,” Biochemical Pharmacology, Vol. 19, No. 1, 1970, pp. 27-34. doi:10.1016/0006-2952(70)90326-6

[22] S. M. Blättner, F. Rencurel, M. R. Kaufman and U. A. Meyer, "In the Regulation of Cytochrome P450 Genes, Phenobarbital Targets LKB1 for Necessary Activation of AMP-Activated Protein Kinase,” Proceeding of the $\mathrm{Na}$ tional Academy of Science of the United States of America, Vol. 104, No. 3, 2007, pp. 1045-1050.

[23] J. L. Harvey, A. J. Paine, P. Maurel and M. C. Wright, "Effect of the Adrenal 11-B-Hydroxylase Inhibitor Metyrapone on Human Hepatic Cytochrome P-450 Expression: Induction of Cytochrome P-450 3A4,” Drug Metabolism and Disposition, Vol. 28, No. 1, 2000, pp. 96-101.

[24] C. Parthasarathy, S. Yuvaraj, R. Sivukumar, B. Ravi Sankar and K. Balasubramanian, "Metyrapone-Induced Corticosterone Deficiency Impairs Glucose Oxidation and Steroidogenesis in Leydig Cells of Adult Albino Rats," Endocrine Journal, Vol. 49, No. 4, 2002, pp. 405-412. doi:10.1507/endocrj.49.405

[25] G. Bannenberg, H.-J. Martin, I. Bélai and E. Maser, “11B-Hydroxysteroid Deshydrogenase Type 1: Tissue-Specific Expression and Reductive Metabolism of Some Anti-Insect Agent Azole Analogue of Metyrapone,” Chemico-Biological Interactions, Vol. 143-144, 2003, pp. 449-457. doi:10.1016/S0009-2797(02)00183-7

[26] B. Testa and P. Jenner, "Inhibitors of Cytochrome P-450s and Their Mechanism of Action," Drug Metabolism Reviews, Vol. 12, No. 1, 1981, pp. 1-117. doi:10.3109/03602538109011082

[27] B. Darvas, I. Bélai, A. Fónagy, P. Kulcsár and M. H. Tag El-Din, "Lethal Disturbances in Larval Development of Neobellieria Bullata Caused by Metyrapone Derivatives,” Pesticide Science, Vol. 32, No. 2, 1991, pp. 133-139. doi:10.1002/ps.2780320202 
[28] L. Roumen, M. P. A. Sanders, K. Pieterse, P. A. J. Hilbers, R. Plate, E. Custers, M. D. Gooyer, J. F. M. Smits, I. Beugels, J. Emmen, H. C. J. Ottenheijm, D. Leysen and J. J. R. Hermans, "Construction of 3D Models of the CYP11B Family as a Tool to Predict Ligand Binding Characteristics," Journal of Computer Aided Molecular Design, Vol. 21, No. 8, 2007, pp. 455-471. doi:10.1007/s10822-007-9128-9

[29] M. Murray, R. M. Sefton, R. Martini and A. M. Butler, "Comparative Induction of CYP3A and CYP2B in Rat Liver by 3-Benzoylpyridine and Metyrapone,” ChemicoBiological Interactions, Vol. 113, No. 3, 1998, pp. 161173. doi:10.1016/S0009-2797(98)00017-9

[30] G. Fantuzzi, L. Cantoni, M. Sironi and P. Ghezzi, "Inhibitors of Cytochrome P450 Suppress Tumor Necrosis Factor Production,” Cellular Immunology, Vol. 150, No. 2, 1993, pp. 417-424. doi:10.1006/cimm.1993.1209

[31] U. Förstermann, U. Alheid, J. C. Frölich and A. Mülsch, "Mechanisms of Action of Lipoxygenase and Cytochrome P-450-Mono-Oxygenase Inhibitors in Blocking Endothelium-Dependent Vasodilatation,” British Journal of Pharmacology, Vol. 93, No. 3, 1988, pp. 569-578.

[32] D. J. Stuehr and M. Ikeda-Saito, "Spectral Characterization of Brain and Macrophage Nitric Oxide Synthases. Cytochrome P-450-Like Hemeproteins That Contain a Flavin Semiquinone Radical," Journal of Biological Chemistry, Vol. 267, No. 29, 1992, pp. 20547-20550.

[33] A. G. Hildenbrandt, "The Binding of Metyrapone to Cytochrome P-450 and Its Inhibitory Action on Liver Microsomal Mixed-Function Oxidase Reactions," The Biochemical Journal, Vol. 125, No. 2, 1971, pp. 6-8.

[34] R. W. Estabrook, D. Y. Cooper and O. Rosenthal, “The Light Reversible Carbon Monoxide Inhibition of the Steroid C21-Hydroxylase System of the Adrenal Cortex," Biochemische Zeitschrift, Vol. 338, 1963, pp. 741-755.

[35] P. A. Williams, J. Cosme, D. M. Vinkovic, A. Ward, H. C. Angove, P. J. Day, C. Vonrhein, I. J. Tickle and H. Jhoti, "Crystal Structures of Human Cytochrome P450 3A4 Bound to Metyrapone and Progesterone," Science, Vol. 305, No. 5684, 2004, pp. 683-686. doi:10.1126/science.1099736

[36] W. Li, H. Liu, X. Luo, W. Zhu, Y. Tang, J. R. Halpert and H. Jiang, "Possible Pathway(s) of Metyrapone Egress from the Active Site of Cytochrome P450 3A4: A Molecular Dynamics Simulation,” Drug Metabolism and Disposition, Vol. 35, No. 4, 2007, pp. 689-696. doi:10.1124/dmd.106.014019

[37] S. Lupien, R. Richter, S. C. Risen, A. Mirow, J. C. Gillin and R. L. Hauger, "Time Course of the CorticosteroidDopaminergic Interaction during Metyrapone and Dexamethasone Administration," Psychiatry Research, Vol. 58, No. 1, 1995, pp. 23-35. doi:10.1016/0165-1781(95)02646-E

[38] S. Kawato, M. Yamada and T. Kimoto, "Brain Neurosteroids Are 4th Generation Neuromessengers in the Brain: Cell Biophysical Analysis of Steroid Signal Transduction,” Advances in Biophysics, Vol. 37, 2003, pp. 1-48.

\section{doi:10.1016/S0065-227X(03)80002-3}

[39] D. Canet, J. C. Boubel and E. Soulas, "La RMN, Concepts, Méthodes et Applications,” Dunod, Paris, 2002.

[40] E. Dennis and A. Plückthun, "Phosphorus 31P-NMR: Principles and Applications,” Academic Press, London, 1984.

[41] P. Job, "Etude Spectrographique de la Formation de Complexes en Solution et de Leur Stabilité,” Comptes Rendus de l'Académie des Sciences, Vol. 180, 1925, pp. 918-930.

[42] F. Djedaïni, "Etude par RMN des Phénomènes d’Inclusion et d'Adaptation Moléculaire dans les Cyclodextrines Naturelles et les Dérivés Synthétiques,” PhD Thesis, Université de Paris Sud, Paris, 1991.

[43] J. C. Debouzy, A. Gadelle, F. Fauvelle, S. Aous, J. Y. Pailler, E. Gentilhomme, P. Perrin and F. Lhoste, "Is Uranyl Scavenger Hexakis(3,6-Anhydro) Tetrakis(2A,B,D, E-O-Octyl) Cyclomaltohexaose (OCT) Relevant with Biosystems?” Bollettino Chimico Farmaceutico, Vol. 140, No. 1, 2001, pp. 4-8.

[44] B. J. Gaffney, "Pratical Considerations for the Calculation of Order Parameters for Fatty Acid or Phospholipid Spin Labels in Membranes,” In: R. J. Berliner, Ed., Spin Labelling Theory and Applications, Academic Press, New York, 1976, pp. 567-571.

[45] A. Gornicki and A. Gutsze, "In Vitro Effects of Ozone on Human Erythrocyte Membranes: An EPR Study,” Acta Biochimica Polonica, Vol. 47, No. 4, 2000, pp. 963-971.

[46] S. Mabrey and J. M. Sturtevant, "Investigation of Phase Transitions of Lipids and Lipid Mixtures by Sensitivity Differential Scanning Calorimetry," Proceedings of the National Academy of Sciences of the United States of America, Vol. 73, No. 11, 1976, pp. 3862-3866. doi:10.1073/pnas.73.11.3862

[47] E. J. Dufourc, C. Mayer, J. Stohrer, G. Althoff and G. Kothe, "Dynamics of Phosphate Head Group in Biomembranes,” Biophysical Journal, Vol. 61, No. 1, 1992, pp. 42-57. doi:10.1016/S0006-3495(92)81814-3

[48] D. Gorenstein, “31P-NMR: Principles and Applications," Academic Press, London, 1984.

[49] S. Follot, J. C. Debouzy, D. Crouzier, C. EnguehardGueiffier, A. Gueiffier, F. Nachon, B. Lefebvre and F. Fauvelle, "Physicochemical Properties and Membrane Interactions of Anti-Apoptotic Derivatives 2-(4-Fluoro-phenyl)-3-(pyridin-4-yl)imidazo[1,2-a]pyridine Depending on the Hydroxyalkylamino Side Chain Length and Conformation: An NMR and ESR Study," European Journal of Medicinal Chemistry, Vol. 44, No. 9, 2009, pp. 35093518. doi:10.1016/j.ejmech.2008.12.026

[50] K. Wüthrich, "Structure and Dynamics in Proteins of Pharmacological Interest," Biochemical Pharmacology, Vol. 40, No. 1, 1990, pp. 55-62. doi:10.1016/0006-2952(90)90178-N

[51] M. P. Besenicar, A. Bavdek, A. Kladnik, P. Macek and G. Anderluh, "Kinetics of Cholesterol Extraction from Lipid Membranes by Methyl-[Beta]-Cyclodextrin-A Surface Plas- 
mon Resonance Approach,” Biochimica et Biophysica Acta, Vol. 1778, No. 1, 2008, pp. 175-184.

[52] S. Bernèche, M. Nina and B. Roux, "Molecular Dynamics Simulation of Melittin in a Dimyristoylphosphatidylcholine Bilayer Membrane,” Biophysical Journal, Vol. 75, No. 4, 1998, pp. 1603-1618.

doi:10.1016/S0006-3495(98)77604-0

[53] J. C. Debouzy, D. Crouzier and E. Flahaut, "Hydrophobic Double Walled Carbon Nanotubes Interaction with Phopholipidic Model Membranes: 1H-, 2H-, 31P NMR and ESR Study," Environmental Toxicology and Pharmacology, Vol. 30, No. 2, 2010, pp. 147-152.

\section{doi:10.1016/j.etap.2010.05.002}

[54] B. Cybulska, M. Herve, E. Borowski and C. M. GaryBobo, "Effect of the Polar Head Structure of Polyene Macrolide Antifungal Antibiotics on the Mode of Permeabilization of Ergosterol- and cholesterol-Containing Lipidic Vesicles Studied by 31P-NMR,” Molecular Pharmacology, Vol. 29, No. 3, 1986, pp. 293-298.

[55] J. I. Kaplan and G. Fraenkel, "NMR of exchanging systems,” Academic Press, New York, 1980.

[56] J. H. Fuhrhop and J. Koning, "Membranes and Molecular Assemblies: The Synkinetics Approach,” Chemistry TRSo, Cambridge, 1994. 